\title{
Optimal Integration of Heat Exchanger and Chimney: Water Recyclability from Kitchen Exhaust
}

\author{
${ }^{[1]}$ Raaghav Aadithya R R, ${ }^{[2]}$ Yokesh R, ${ }^{[3]}$ Naveen Raj S

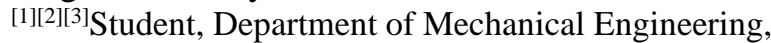 \\ Rajalakshmi Engineering College, Tamil Nadu, India.
}

\begin{abstract}
Recycling water is being a significant purpose in a day to day life, especially in gulf countries and deserted areas due to the lack of sufficient water. Since a little drop of water makes the mighty ocean, each and every drop of water makes sense. This paper mainly concentrates on condensing water from a kitchen chimney exhaust and recycling and reusing the condensed water. The steam evaporated while cooking is filtered in a chimney by a filter that is fitted with the chimney, thus the filtered steam flows through the duct and then passes by a heat exchanger thereby converting steam into water. So the condensed water can be considered for a different purpose from the waste stream generated by chimneys. Further, this paper concerns a straight line chimney with a ducted variant.
\end{abstract}

Keywords-Chimney; condensing; duct; filtered; recycling; heat exchanger; steam; straight-line chimney;

\section{INTRODUCTION}

The world population is around 7.8 billion and still increasing which leads to many serious problems, one such is water scarcity. Water covers two-thirds of our planet, and it is easy to come to the conclusion that it is sufficient. But most of which is covered by the sea (salt water). But still, the amount of freshwater that we use for drinking, farming is limited. Around $3 \%$ of the world water is freshwater out of which twothird is locked in the glacial mass which cannot be used. Due to which almost 1 Billion people cannot use freshwater around the world which leads to many diseases in many developing countries. To solve these problems we must reduce reuse and recycle the available water. Each and everyone in our house can take a remedial measure to limit the usage.

We use a lot of water in our kitchen during cooking which is simply let into the atmosphere as steam. We use chimneys to absorb steam and release in the atmosphere. The chimney is a device that is used to provide ventilation. It is used to absorb the toxic and hot gasses (i.e gasses released from the stove and furnaces) from the kitchen room. It is mostly made up of clay or metal. The Chimneys are found in a vertical shape to ensure the smooth flow of gasses to ensure the Chimney effect(stack effect). The height of the chimney influences the ability to transfer flue gas due to the stack effect. The tube-like structure was first used by the people of Rome to remove the gases from the bakeries which were found in northern Europe during the 12 th century.

Our upgrade in the modern chimney helps us to collect the water which is simply let into the atmosphere as steam. We condense steam using a condenser to condense the water in the steam and use it for household functions.

\section{COMPONENTS}

\section{A. Filter}

A filter is one of the important components present in the modern electric chimney. It is used to capture the oil particles and releases fresh air which contains water vapor. There are three types of filters which are commonly used in modern chimney they are:

1. Mesh filter

2. Baffle filter

3. Charcoal filter

The mesh filters are used in the above mentioned chimney as it can be utilized for duct and ductless chimney. It has aluminum layers meshing on each other which forms the small pores which traps the oil particles and spices. This type of filter requires high maintenance as the pores gets clogged easily. If it is not maintained the efficiency of the chimney is decreased but the cleaning of this filters is easy it just requires warm soapy water or detergent

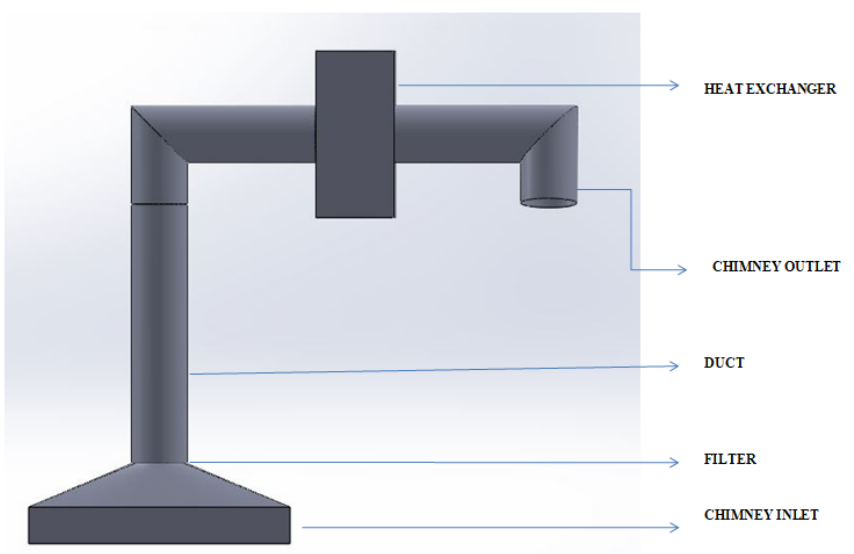

Fig.1 3D View

\section{B. Unidirectional valve}

The flow direction of the steam is controlled by the installation of unidirectional valves in the duct of the chimney. The steam is supplied into the heat exchanger at a particular pressure. The heat exchanger operates at a specific pressure where it comes into contact with the heat exchanging surfaces. These steam stopping valves are used to avoid the backflow of steam during the process. The flow is restricted by using a 
screw adjuster which blocks the airway by reducing the airflow rate. The airflow will be active only on one side and if the steam flows back then the sprung valve will stop the airflow this will force the steam in the required direction.

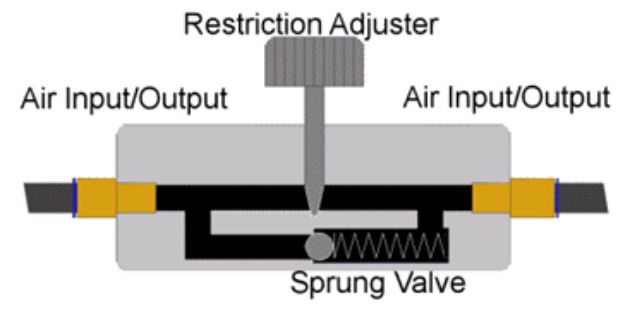

Fig.2 Unidirectional

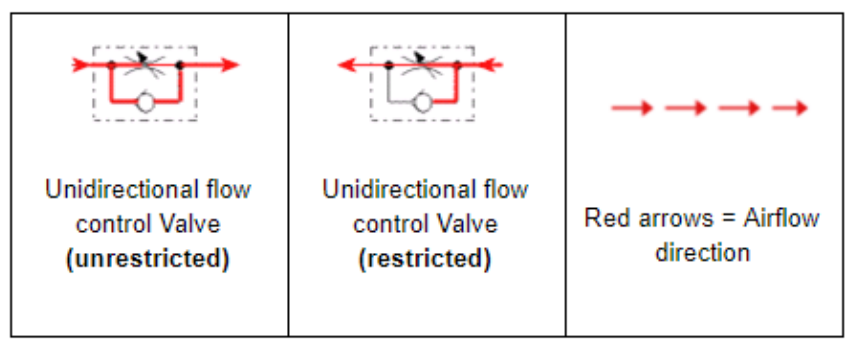

Fig.3 Valve Operation

\section{Heat exchanger}

The steam is condensed into water using a heat exchanger. It is based on the convection process (i.e. the heat flows from higher temperature to lower temperature) here vapor is at high temperature and the cold water passed through the pipe are at lower temperature. The cold water is passed in counter flow direction which collects the heat from the vapor and condenses it.

Shell and tube type heat exchanger are used in the above chimney. It contains a large number of tubes poached in a shell. Heat transfer occurs between two fluids. Baffles are installed on the shell sides to produce effective heat transfer due to turbulence and it also supports the long tubes from vibrations.

\section{PROCESS}

The gases produced during cooking are not only water vapor it also has many impurities like cooking oil, grease, etc. To filter these impurities we use a filter in our chimney which could be later removed and cleaned during monthly maintenance. The charcoal filter used here filters the cooking oil and other impurities and just liberates water vapor. The water vapor moves into the duct through a unidirectional valve which is used to avoid the backflow of water vapor in the chimney. Then the water vapor enters into the heat exchanger which condenses the water vapor into the water by the flow of cold water in the counter-flow direction in the heat exchanger and comes out and the water is then collected at the end of the duct. Thus the water which is collected can be removed later and reused.

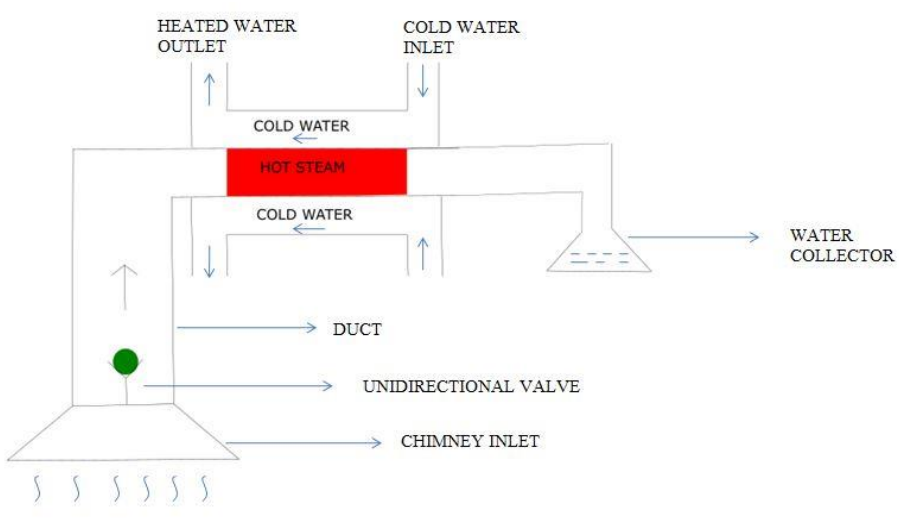

Fig.4 Schematic View

\section{CALCULATION}

Assumptions: -

Steam temperature $\mathrm{T}_{1}=120^{\circ} \mathrm{C}$

Inlet temperature of heat exchanger $\mathrm{t}_{1}=25^{\circ} \mathrm{C}$

Outlet temperature of heat exchanger $\mathrm{t}_{2}=80^{\circ} \mathrm{C}$

Unit mass flow rate $-1 \mathrm{~kg} / \mathrm{sec}$

Heat lost by the hot fluid $=$ heat gained by the cold fluid

$Q_{\text {ip }}=Q_{c}$

$\dot{m}_{\text {ph }} C_{\text {pli }}\left(T_{1}-T_{2}\right)=\dot{m}_{e} C_{\mathrm{pe}}\left(t_{2}-t_{1}\right)$

$1 \times 4180\left(120-T_{2}\right)=1 \times 4180(80-25)$

$T_{2}=65^{\circ} \mathrm{C}$

So, the outlet temperature of water is $65^{\circ} \mathrm{C}$

Logarithmic Mean Temperature Difference of the fluids in heat exchanger is expressed as (Assuming counter flow)

$$
\begin{aligned}
& (\Delta T)_{m}=\frac{\left[\left(T_{1}-t_{2}\right)-\left(T_{2}-t_{1}\right)\right]}{\ln \left(\frac{T_{1}-t_{2}}{T_{2}-t_{1}}\right)} \\
& (\Delta T)_{m}=\frac{[(120-80)-(65-25)}{\ln \left(\frac{120-80}{65-25}\right)}
\end{aligned}
$$

$(\Delta T)_{m}=12.5^{\circ} \mathrm{C}$

Heat transfer rate:

$Q_{\hat{h}}=m_{h_{h}} C_{p h i}\left(T_{1}-T_{2}\right)$

$\mathrm{Q}_{\mathrm{h}}=229.9 \mathrm{~kW}$

$\mathrm{Q}=\mathrm{UA}(\Delta \mathrm{T})_{\mathrm{m}}$

Assuming $\mathrm{U}=2300 \mathrm{~W} / \mathrm{m}^{2} \mathrm{~K}$ - from pg. 156 - HMT data

Book; Steam to water

$2299000=2300 \times \mathrm{A} \times 12.5$

$\mathrm{A}=7.99 \mathrm{~m}^{2}=8 \mathrm{~m}^{2}$.

\section{CONCLUSION}

It can be concluded that by installing Heat exchanger with the chimney in order to minimize the outlet temperature of exhaust. The outlet of the chimney is condensed and can be collected in a water collector as a liquid around $65^{\circ} \mathrm{C}$ (theoretically).If the inlet temperature of the steam to be $120^{\circ} \mathrm{C}$ and inlet temperature of cooling to be $25^{\circ} \mathrm{C}$ and outlet temperature to be $80^{\circ} \mathrm{C}$. This optimal condition is possible when the area of heat transfer is around $8 \mathrm{~m}^{2}$. 


\section{REFERENCE}

[1]. Carlos Mender; Yusuf Bicer; Integration of Solar Chimney with desalination for sustainable water product: Thermodynamic Assessment, Case Study in Thermal Engineering

[2]. Shehryar Ishaque; Irfanul Haque Siddique;Man- Hoe Kim; Effect of heat exchanger Design on seasonal performance of heat pump system, International Journal of heat and mass transfer.

[3]. Zelalem Tadesse; Boiler Design and Safety, Slide Share.

[4]. Sachin Thorat; Type of Heat Exchanger, Learn Mech.

[5]. Engineering Essential: Heat Exchanger, Hydraulic \& Pneumatics . 